\title{
Implementation Strategies for Improving the Care of Depressed Elderly Persons-Summary of an International Workshop
}

\author{
Elisabeth Severinsson*, Anne Lise Holm \\ Centre for Women's, Family and Child Health, Faculty of Health Sciences, Buskerud \& Vestfold University \\ College, Kongsberg, Norway \\ Email: ${ }^{*}$ elisabeth.severinsson@hbv.no, anne.holm@hsh.no
}

Received 13 August 2014; revised 15 September 2014; accepted 1 October 2014

Copyright (C 2014 by authors and Scientific Research Publishing Inc.

This work is licensed under the Creative Commons Attribution International License (CC BY).

http://creativecommons.org/licenses/by/4.0/

(c) (i) Open Access

\section{Abstract}

The aim of the study was to identify the most important research priorities as well as future strategies for promoting and implementing evidence-based care of depressed elderly persons. An interdisciplinary workshop was organized using a focus group format and the transcript of the discussion was interpreted by means of the qualitative content analysis. The most important research priorities for improving the care of depressed elderly persons, implementation levels, theoretical approaches as well as possible outcomes were analysed on individual consumer, healthcare system, and policy level. A wide range of theories and methods are necessary to identify and explain implementation processes and results. Qualitative and quantitative methodologies in combination with knowledge synthesis were discussed. In addition, the need to summarize the literature in terms of specific issues was emphasized. In conclusion, the implementation strategies for improving the care of depressed elderly persons should be addressed on three levels: individual consumer, healthcare system and policy. Although some aspects of the implementation model may need to be enhanced, the fact that it includes conditions on individual level, i.e. self-management support, is of importance. The expansion and maintenance of evidence-based care generate potential for change in mental healthcare, thus improving outcomes for individual elderly patients. Areas that require further research are organization, cost and leadership. The use of mixed methods could strengthen future studies. Implementation researchers need a broad repertoire in order to plan and perform evidence-based research. To improve practice, implementation strategies should be developed in clinical and community guidelines.

\footnotetext{
${ }^{*}$ Corresponding author.
} 


\section{Keywords}

\section{Implementation Research, Depression, Elderly, Professional Guidelines, Workshop}

\section{Introduction}

This paper presents experts' perceptions of interdisciplinary research priorities and future evidence-based implementation strategies in the care of depressed elderly persons. Depression is a leading chronic illness worldwide and the third most common reason for primary care consultations [1]. In recent years, mental illness, especially depression, anxiety, and alcohol-related problems, has increased among the elderly [1]-[3]. An important question is how research can contribute to improved practice by means of an implementation approach. Implementation research involves evidence-based strategies to promote and optimize the quality and effectiveness of health services. Proctor et al. [4]) defined implementation as the effects of deliberate and purposive actions to introduce new forms of treatment, practices and services.

Implementation research often focuses on the strategies required to deliver or introduce new interventions, here called "implementation strategies", to distinguish them from clinical and community health interventions. A framework for conceptualizing and measuring implementation outcomes based on variables such as "acceptability", "appropriateness", and "feasibility" can be used to understand how well a given implementation process actually functions [5]. Broadly speaking, the term implementation research describes the scientific study of the processes used in the implementation of initiatives as well as the contextual factors that affect them [5]. Typical implementation strategies include: (1) enhancing the capabilities of government (public policy, control and financing); (2) improving implementation performance of provider organizations; (3) strengthening the capabilities and performance of individual providers and front-line workers; (4) empowering communities and households; and (5) supporting multiple stakeholders involved in improvement [6].

According to Wallin [7], the use of theories is one way of developing knowledge translation (KT) and evidence based practice (EBP). Theories derived from research constitute the foundation of EBP in virtually all healthcare disciplines. Investigating the effectiveness of implementation strategies will enhance efficiency in the context of mental health. These theories can facilitate the description of different aspects, as well as the presentation of a testable hypothesis and discussion of the outcomes of a study. When reviewing the history of KT in nursing it is striking that rigorous research evaluating interventions aimed at changing nurses' behavior is still scarce [7]. Grol et al. [8], made a distinction between impact and process theories, where the former describe how an intervention will facilitate change and the latter can be used for planning and organizing implementation activities.

Dissemination of research by educating healthcare professionals and leaders involves different theoretical models and methodological approaches [9]. However, innovative approaches that enhance patient and system outcomes require motivation and engagement [10] as well as research capacity [11], collaboration [12], and communication skills [9]. There are many interventions available for change of practice, and education is not necessarily the sole implementation strategy, especially as it has been demonstrated that traditional didactic education does not have much potential for bringing about change [13]. In 2013 our research team conducted exploratory studies on interview data to evaluate successful implementation with the aim of improving the care of depressed elderly persons [14]-[16]. Holm and Severinsson [17] suggested the need for a strong emphasis on organizational change, leadership as well as a common goal and vision. Therefore another study was undertaken to explore the above findings in more detail and strengthen the understanding of implementation outcomes such as the effect of setting the most important research priorities, future implementation strategies as well as theoretical and methodological developments relevant to mental health in the context of elderly persons, a population at risk of depression.

The aim of the study was to identify the most important research priorities as well as future implementation strategies for promoting evidence-based implementation strategies in care of depressed elderly persons.

\section{Methods}

We organized an interdisciplinary workshop to discuss the findings from national and international studies on future implementation strategies in the care of depressed elderly persons. We applied focus group methodology 
in a new interdisciplinary context where both clinical and academic researchers participated in the identification of research pertaining to depressed elderly persons living in the community. This design was expected to contribute to identification of the most important research priorities as well as to theoretical and methodological aspects of future research on this target group.

\subsection{Data Collection and Participants}

Data were collected from skilled interdisciplinary researchers, all experts in the field of depression. Eleven researchers from five disciplines (public health, nursing, psychology, mental health, and psychiatric care) were invited to participate. All had a doctoral degree in Health Sciences; Public Health (2), Doctor of Medical Science (3), Psychiatric Care (2) and Mental Health Nursing (2) in addition to which two had a doctoral degree in Psychology (2). All agreed to attend the scientific workshop, which was of three hours duration (including a 15 minutes break) and followed the principles of a focus group discussion with the aim of obtaining advanced evidence-based knowledge in the field of depression [18]. Some also had experience of research on suicide, while others were familiar with social capacity among depressed elderly people and their family members. There were also experts on different levels of healthcare as well as methodology and research design including implementation research. The average experience of utilizing research was about 20 years. The participants represented seven countries; Finland, Sweden, Denmark, Norway, Canada, the USA, and Cyprus. The workshop and focus group interview was facilitated by the primary investigator (ES) in a four-year intervention outlined in the three-part Norwegian Research Council project; “Chronic Disease Management-Implementation and coordination of healthcare systems for depressed elderly persons". The group process included iterative discussions of experiences of the topic from the experts' countries as well as their recommendations and ideas for developing a research agenda for the target group.

\subsection{Ethical Considerations}

Approval for the study was granted by The Regional Ethics Committee of Western Norway (No. 2010/2242). To protect the confidentiality of the participants, the findings from the focus group interview were reported as generalisations and unattributed quotations. All participants gave their oral consent to participate and to the use of a tape-recorder.

\subsection{Data Analysis}

The focus group discussions were audiotaped, transcribed, scanned, analyzed, and interpreted by the two authors. The statements were reflected on to clarify their meanings, which were then interpreted through a process of iterative reading and discussion of possible themes throughout various stages of interpretation [19]. During the second stage of the analysis, the researchers refined the research priorities and attempted to portray various implementation outcomes across disciplines (Table 1). This iterative process combines elements of content and thematic analysis [20].

\section{Results}

All participants presented key points and the specific conditions pertaining in the country they represented.

The meaningful involvement of the participants in terms of engaging in and making suggestions about the development of research contributed increased insight into research priorities. The level of interaction in the group was high, which enhanced reflection as well as the group dynamic. The evidence that emerged from the focus group can be described on three levels; individual consumer, health care system, and policy. The most important research strategies, i.e., implementation, theoretical approaches, and possible outcomes, for improving the care of depressed elderly persons are presented. They were guided by the following questions: What should be improved and investigated? What theoretical model and methodological approach should be used? and What are the likely outcomes of implementation?

\subsection{Implementation Strategies-Individual Consumer Level}

Findings from the individual consumer level were related to experiences of suffering from depression. Six possible 
Table 1. Overview of research priorities; implementation strategies and levels, theoretical approaches and possible outcomes of improved care of depressed elderly persons.

\begin{tabular}{|c|c|c|}
\hline \multicolumn{2}{|c|}{ Implementation strategies and levels } & Possible outcomes of implementation \\
\hline Individual consumer level & $\begin{array}{l}\text { Chronic Care Model } \\
\text { Person-centered care } \\
\text { Community-oriented care }\end{array}$ & $\begin{array}{l}\text { Satisfaction with care } \\
\text { Disparity in prevalence rates between women and men } \\
\text { Reduction of mental deprivation } \\
\text { Increased accessibility of care } \\
\text { Reduction of inactivity and stigma } \\
\text { Feelings of hope, dignity, } \\
\text { meaningfulness and worthiness }\end{array}$ \\
\hline $\begin{array}{l}\text { Healthcare system level } \\
\text { Individual healthcare } \\
\text { professionals }\end{array}$ & $\begin{array}{l}\text { Case management } \\
\text { Interpersonal and psycho-social interventions } \\
\text { Community care team } \\
\text { Capacity building } \\
\text { Education } \\
\text { Clinical and community guidelines for healthcare } \\
\text { professionals, especially psychiatric nurses }\end{array}$ & $\begin{array}{l}\text { Safe quality care } \\
\text { Low threshold } \\
\text { "a single entry point” }\end{array}$ \\
\hline Policy level & $\begin{array}{l}\text { Reforms to improve mental health } \\
\text { User involvement } \\
\text { Financial aspects }\end{array}$ & $\begin{array}{l}\text { The need for a strategy to reduce stigma by making } \\
\text { mental health issues more visible in society. } \\
\text { Social inclusion }\end{array}$ \\
\hline
\end{tabular}

*Special description of the title. (dispensable).

outcomes of implementation emerged: Satisfaction with care; Disparity in prevalence rates between women and men; Reduction of mental deprivation; Increased accessibility of care; Reduction of inactivity and stigma as well as Feelings of hope, dignity, meaningfulness, and worthiness.

During part of the meeting, members of the focus group identified and discussed the topic of satisfaction with care and the evidence of the strong relationship between suicide and physical illness such as heart attack, diabetes, Chronic obstructive pulmonary disease (COPD), and metastatic cancer, especially in the acute phase. It was stated that different implementation strategies are required depending on whether depression is viewed as a social or an existential, and thus psychological phenomenon. The disparity between men and women in terms of health problems was also raised. The discussion centered on health problems related to the increased rates of depression and suicide and the need to improve implementation both on the individual consumer and on the healthcare system level in order to ensure satisfaction with care as well as reducing mental deprivation and inactivity. Individual consumers' need to be confirmed and experience feelings of hope and dignity was discussed.

A wide range of theories and methods are necessary to identify and describe implementation and its outcomes as processes. Several theoretical approaches and models were reported to be important for explaining and implementing safe quality care. The strategy for implementing evidence-based care presupposes knowledge of public policy and guidelines, such as those for psychiatric nurses. Models and theories discussed with regard to the individual level included; the Chronic Care Model, Person-centered care, and Community-oriented care.

\subsection{Implementation Strategies-Healthcare System and Policy Levels}

At the healthcare system level, i.e., individual professionals, two possible implementation outcomes emerged: Safe quality care and Low threshold "a single entry point". Different theoretical approaches were reported such as Case Management, Interpersonal and psycho-social interventions, Community care team, and the Capacity Approach. In addition, the importance of clinical and community practical guidelines for healthcare professionals, more specifically psychiatric nurses, was highlighted. In the discussion the need for education and capacity building for healthcare professionals was also raised.

At policy level two possible areas outcomes of implementation emerged: The need for a strategy to reduce stigma by making mental health problems more visible in society and Social inclusion. On this level, several reforms to improving mental health, user involvement and financial aspects were mentioned. Various reforms should be included in the tentative research agenda in order to increase the linkages to national and international guidelines. Interpersonal and psycho-social interventions in combination with psycho-pharmacological treatment were mentioned as was the WHO "Active Ageing" [21] as well as Nordic and European reforms, such as The Finnish Public Health Programme [22], that focuses on functional ability of older adults, the ageing policy 
and Care Services for Older People Act, the National Development Programme for Social Welfare and Health Care, the Norwegian New Health Sector Reform, the Coordination Reform [23] and the Swedish, National Health and Welfare Guidelines for Care of Depression and Anxiety Disorders [24].

The methodological aspects of feasibility research included qualitative and quantitative methodologies as well as knowledge synthesis for summarizing the literature on specific questions. The discussion continued by outlining possible paradigmatic approaches, common qualitative designs, and their philosophical frameworks. The different paradigmatic perspectives or philosophies that underpin both qualitative and quantitative research were discussed. There is a strong tradition of studying depression by means of population surveys, controlled, and observational designs as well as Randomized Control Trials (RCTs) in order to obtain more generalizable findings that can directly inform practice and policy. Evaluations of interventions, mixed methods, and triangulated findings are less common, which also applies to studies with a hermeneutical phenomenological design i.e., the lived experiences of adult recipients of care interventions. The goal of phenomenology is to develop understanding of a problem through individual human experiences of a certain phenomenon in their life-world. A critical view of the emphasis on biological, psycho-pharmacological treatment rather than interpersonal skills emerged and was discussed.

\section{Discussion}

The evaluation of future research implementation strategies for improving the care of depressed elderly persons highlighted their need for individual treatment and support to increase self-management in daily life. This was obvious in relation to their satisfaction with care, their need for accessibility and wish to have their suffering confirmed. The disparity between women and men was addressed. There is a disparity in prevalence rates between women and men, which is believed to be due to "true differences" as opposed to artifactual effects such as variations in help-seeking or symptom reporting [25]. Depression is the most frequently encountered mental health problem in women and, according to the WHO [1], the most significant one. In community samples, the lifetime risk of major depression for women ranges from 10\% - 25\% for women (American Psychiatric Association [APA] [26]. It is likely that widows in developed countries fit the criteria for major depression [27]. Women's help-seeking behavior has been described in the literature, where women are reported to be more vulnerable, passive, dependent, and at risk of depression. These findings correspond with those of two large-scale international studies, the EURODEP [28] and the SHARE study [29], which unfortunately did not provide age groupspecific prevalence rates, but suggested that in later life, age and gender are influenced by two factors, affective suffering (including depression, tearfulness, suicidality, sleep problems) and motivational factor (comprising enjoyment, interest, concentration). Women scored higher on the affective suffering factor, while advanced age scored higher on the motivational factor [30]. Horvath [31] presented various stages of women's experiences of depression. A recurrent theme in the findings was that depressed women tend to apply negative socially-derived and externally-imposed frames of reference, becoming entrapped in cognitive constructs by which they evaluate their self-worth. The self was seen as rejected, subordinate, and a passive victim of hostile circumstances.

A systematic review of older persons' narratives when suffering from depressive ill-health revealed three themes; "the need for courage, strength, and self-reliance", "the meaning of responsibility", and "wearing a mask of normalcy to hide the shame" [15]. Moreover, exploring older persons' lived experiences of depression and self-management revealed the theme "relationships and togetherness" [32]. A collaborative approach can therefore be important for empowering older persons through self-development and management. This is also confirmed by Lyberg et al. [16], who found experiences of struggling with feelings of belongingness and aloneness in relationships with family members, as well as a sense of being worthy and unworthy. The family plays a vital role, not always by direct assistance but indirectly by supporting the older person's guiding principles for managing her/his situation. Other studies highlighted the risk and the meaning of survival when suicidal [33]. This is important for practical implications due to the fact that mental healthcare professionals might be able to reduce the risk of suicide and perturbation by helping depressed older people to explore, resolve and ultimately come to terms with their unresolved historical issues [33].

Depression in older persons is an increasingly complex health problem due to the difficulties involved in distinguishing between depression and symptoms of physical ill health, dementia, normal aging, and grief [34]. Wade \& Cairney [35], reported that the prevalence of depression in a Canadian survey decreased until the age of 65, after which there was a slight increase in both women and men. According to Fässberg [36], 6\% of Euro- 
peans over the age of 65 years reported a death wish and functional disability was independently associated with such a wish. Having one or more chronic conditions was also associated with wishing for death among men and women [36]. Suicide has been estimated to be a risk factor that is particularly salient in men [37]. However, Lebret et al. [38] found that an elderly person who attempts suicide was most likely to be a widow suffering from social isolation, loneliness, and depression. This is supported by Stroebe et al. [39], who also found that suicidal ideation was higher among widowed people in general and widows in particular. Increased suicidal thoughts and actions in bereavement were associated with extreme emotional loneliness and severe depressive symptoms. Women are frequently found to have greater suicidal ideation and a higher rate of suicide attempts than men. Stroebe et al. [39] suggested that widows are at extremely high risk of suicidal ideation, particularly in view of results indicating a close association with severe depressive symptoms. Paradoxically, the prevalence of actual suicide is higher in bereaved men than in bereaved women.

Previous research in the Norwegian context demonstrated that elderly individuals who attempted suicide perceived that everything that had given value to their lives had been lost, life was increasingly experienced as a burden, and their perception of themselves was "losing oneself" [40]. Holm and Severinsson [14] revealed one main theme: "a struggle to perceive meaning in the meaningless". The widows seemed overwhelmed by the need to master an unbearable emotional state. The resilience process was experienced as a struggle, and time was required to improve their well-being and self-management. To achieve self-management, nurses should strengthen widows' optimism, control, well-being, and the pathways that lead to recovery.

\subsection{Implementation Outcomes Guided the Healthcare System}

A wide range of theories and methods are necessary for identifying and explaining implementation processes and outcomes [41]. In this study it was suggested that the Chronic Care Model (CCM) enables better management of long-term conditions, such as depression, in primary care settings. Holm and Severinsson [17] revealed that the barriers such as lack of organizational, administrative, and professional ability as well as the absence of clarity pertaining to managers' responsibility for the promotion of patient self-management hinder the implementation of the CCM. Facilitators of success reported were leadership support and vision as well as redesigning the delivery system. Thus, in order to create an environment for organizational change, leadership and professionals must work toward a common goal and vision. Another study based on the CCM demonstrated lack of effective community team leadership in the community, the need to change the delivery system and improve self-management support for depressed older persons, as well as the participation of their families [9]. In the latter study it was concluded that nurse managers should find ways of supporting the depressed older persons by better structuring the care, increasing cooperation with organisational leadership, and creating an environment characterised by trust and mutual respect. Distrust can have serious implications for discharge planning collaboration. In addition, ethical dilemmas can raise when promoting consumers self-management [42], among other things due to lack of trust in the community healthcare system commitment to bringing about effectiveness and change. In an evaluative study comprising healthcare team members, the importance of ensuring a pathway to the top level of the organization, the need for leadership from senior managers, the necessity of formalizing collaboration, and increasing self-management were highlighted [10]. Senior managers should cooperate with specialist care givers and administrators in the community and redesign the delivery system to facilitate teamwork and the self-management ability of depressed older persons.

\subsection{Methodological Considerations}

A limitation of this study is the qualitative approach. For a deeper understanding of the reforms mentioned, a document analysis can be enhanced by skimming (superficial examination), reading (thorough examination) and interpretation [20]. Our intention was not to compare implementation strategies between different countries in order to improve the care of depressed elderly persons. However, in future research it would be valuable to use a mix method approach in a comparative study.

\section{Conclusion}

In conclusion, the implementation strategies for improving the care of depressed elderly persons should be addressed on three levels; individual consumer, healthcare system and policy. Although some aspects of the im- 
plementation model may need to be enhanced, the fact that it includes conditions on individual level, i.e. selfmanagement support, is of importance. The expansion and maintenance of evidence-based care generate potential for change in mental healthcare, thus improving outcomes for individual elderly patients. Areas that require further research are organization, cost and leadership. The use of mixed methods could strengthen future studies. Implementation researchers need a broad repertoire in order to plan and perform evidence-based research. To improve practice, implementation strategies should be developed in clinical and community guidelines. In order for research to better target the needs of individual consumers, new pathways to understanding depressed elderly persons can be identified by are questions such as: How can elderly persons become more visible in society? and How can attitudes toward older people be changed in order to preserve their dignity?

\section{Competing Interests}

The authors declare that there is no conflict of interest.

\section{Authors' Contributors}

The study was designed and the protocol written by ES and ALH. ES coordinated the research. ALH was responsible for the data collection, which took the form of interviews and electronic reviews. ALH and ES participated in the data analysis and interpretation. The report was written by ES and ALH.

\section{Acknowledgements}

This is a report of the project entitled 'Chronic Disease Management-Implementation and coordination of healthcare systems for depressed elderly persons', funded by the Research Council of Norway (Grant No. 204238/V50) from 2010-2014. We are grateful to the experts who participated in the workshop as well as to Gullvi Nilsson and Monique Federsel for reviewing the English language.

\section{References}

[1] World Health Organization (WHO) (2012) Depression Is a Common Illness and People Suffering from Depression Need Support and Treatment. http://www.who.int/mediacentre/news/notes/2012/mental_health_day_20121009/en/

[2] Batterham, P.J., Christensen, H. and Alison, L.C. (2013) Anxiety Symptoms as Precursors of Major Depression and Suicidal Ideation. Depression and Anxiety, 30, 908-916.

[3] Chou, K.L. and Cheung, K. (2013) Major Depressive Disorder in Vulnerable Groups of Older Adults, Their Course and Treatment, and Psychiatric Comorbidity. Depression and Anxiety, 30, 528-537. http://dx.doi.org/10.1002/da.22073

[4] Proctor, E., Silmere, H., Raghavan, R., Hovmand, P., Aarons, G., Bunger, A., Griffey, R. and Hensley, M. (2011) Outcomes for Implementation Research: Conceptual Distinctions, Measurement Challenges, and Research Agenda. Administration and Policy in Mental Health, 38, 65-76. http://dx.doi.org/10.1007/s10488-010-0319-7

[5] Peters, D.H., Nhan, T.T and Taghreed, A. (2013) Implementation Research in Health: A Practical Guide. Alliance for Health Policy and Systems Research, World Health Organization. http://apps.who.int/iris/bitstream/10665/91758/1/9789241506212_eng.pdf?ua=1

[6] Peters, D.H., El-Saharty S., Siadat B., Janovsky, K. and Vujicic, M. (2009) Improving Health Services in Developing Countries: From Evidence to Action. World Bank, Washington DC.

[7] Wallin, L. (2009) Knowledge Translation and Implementation Research in Nursing. International Journal of Nursing Studies, 4, 576-587. http://dx.doi.org/10.1016/j.ijnurstu.2008.05.006

[8] Grol, R., Bosch, M., Hulscher, M., Eccles, M. and Wensing, M. (2007) Planning and Studying Improvement in Patient Care: The Use of Theoretical Perspectives. The Milbank Quarterly, 85, 93-138. http://dx.doi.org/10.1111/j.1468-0009.2007.00478.x

[9] Holm, A.L. and Severinsson, E. (2013) Interdisciplinary Team Collaboration during Discharge of Depressed Older Persons-A Norwegian Qualitative Implementation Study. Nursing Research and Practice, 2013, Article ID: 794743. http://dx.doi.org/10.1155/2013/794743

[10] Holm, A.L. and Severinsson, E. (2014) Perceptions of the Need for Improvements in Healthcare after Implementation of the Chronic Care Model. Nursing\& Health Sciences. (Pub Ahead of Print) http://dx.doi.org/10.1111/nhs.12136

[11] Severinsson, E. (2014) Capacity Building_Challenges for Nurse Managers. Journal of Nursing Management, 22, 407409. http://dx.doi.org/10.1111/jonm.12209 
[12] Andvig, E., Syse, J. and Severinsson, E. (2014) Interprofessional Collaboration in the Mental Health Service in Norway. Nursing Research and Practice, 2014, Article ID: 849375. http://dx.doi.org/10.1155/2014/849375

[13] Grol, R. and Grimshaw, J. (2003) From Best Evidence to Best Practice: Effective Implementation of Change in Patients' Care. The Lancet, 362, 1225-1230. http://dx.doi.org/10.1016/S0140-6736(03)14546-1

[14] Holm, A.L. and Severinsson, E. (2013) A Systematic Review of Emotional State and Self-Management among Widows. Nursing and Health Sciences, 14, 109-120. http://dx.doi.org/10.1111/j.1442-2018.2011.00656.X

[15] Holm, A.L. and Severinsson, E. (2014) Surviving Depressive Ill-Health: A Qualitative Systematic Review of Older Persons' Narratives. Nursing and Health Sciences, 16, 131-140. http://dx.doi.org/10.1111/nhs.12071

[16] Lyberg, A., Holm, A.L., Lassenius, E., Berggren, I. and Severinsson, E. (2013) Older Persons’ Experiences with Depressive Ill-Health and Family Support. Nursing Research and Practice, 2013, Article ID: 837529. http://dx.doi.org/10.1155/2013/837529

[17] Holm, A.L. and Severinsson, E. (2012) Chronic Care Model for the Management of Depression: Synthesis of Barriers to, and Facilitators of, Success. International Journal of Mental Health Nursing, 21, 513-523. http://dx.doi.org/10.1111/j.1447-0349.2012.00827.x

[18] Morgan, D.L. (1997) Focus Groups as Qualitative Research. Sage Publication, London.

[19] Gadamer, H.G. (2004) Truth and Method. Interactive Sciences Ltd., Gloucester.

[20] Bowen, G. A. (2009) Document Analysis as a Qualitative Research Method. Qualitative Research Journal, 9, 27-40. http://dx.doi.org/10.3316/QRJ0902027

[21] WHO (2002) Active Aging: A Policy Framework. Geneva. http://whqlibdoc.who.int/hq/2002/who_nmh_nph_02.8.pdf

[22] The Finnish Public Health Programme (2001) Health 2015-Public Health Programme. Ministry of Social Affairs and Health. https://www.julkari.fi/bitstream/handle/10024/114637/Es200108eng.pdf?sequence=1

[23] The Norwegian Ministry of Health and Care Services (2008) The Coordination Reform. Proper Treatment-At the Right Place and Right Time. Report No.47, 2008-2009. http://www.regjeringen.no/upload/HOD/Samhandling\%20engelsk_PDFS.pdf

[24] The Swedish National Board of Health and Welfare (2010) Guidelines for Care of Depression and Anxiety Disorder. http://www.socialstyrelsen.se/nationalguidelines/nationalguidelinesforcareincasesofdepressionandanxietydisorders

[25] Kornstein, S. (2003) Gender, Depression and Antidepressant Treatment. Clinical Focus Primary Psychiatry, 10, 58-61.

[26] American Psychiatric Association (2000) Diagnostic and Statistical Manual of Mental Disorders. 4th Edition, APA, Washington, DC.

[27] Waraich, P., Goldner, E.M., Somers, J.M. and Hsu, L. (2005) Prevalence and Incidence Studies of Mood Disorders: A Systematic Review of the Literature. Canadian Journal of Psychiatry, 49, 124-138.

[28] Copeland, J.R., Beekman, A.T., Braam, A.W., Dewey, M.E., Delespaul, P., Fuhrer, R., Hooijer, C., Lawlor, B.A., Kivela, S.-L., Lobo, A., Magnusson, H., Mannm, A.H., Meller, I., Prince, M.J., Reischies, F., Roelands, M., Skoog, I., Turrina, C., de Vries, M.W. and Wilson, K.C. (2004) Depression among Older People in Europe: The EURODEP Studies. World Psychiatry, 3, 45-49.

[29] Castro-Costa, E., Dewey, M., Stewartm, R., Baerjee, S., Huppert, F., Mendonca-Lima, C., Bulam, C., Reisches, F., Wancata, J., Ritchie, K., Tsolaki, M., Mateos, R. and Prince, M. (2007) Prevalence of Depressive Symptoms and Syndromes in Later Life in Ten European Countries. The SHARE Study. British Journal of Psychiatry, 191, 393-401. http://dx.doi.org/10.1192/bjp.bp.107.036772

[30] Luppa, M., Sikorski, C., Luck, T., Ehreke, L., Konnopka, A., Wise, B., Weyerer, H., König, H. and Riedel-Heller, S. (2012) Age- and Gender-Specific Prevalence of Depression in Latest-Life-Systematic Review and Meta-Analysis. Journal of Affective Disorders, 136, 212-221. http://dx.doi.org/10.1016/j.jad.2010.11.033

[31] Horvath, P., Bissix, G., Sumarah, J., Crouchman, E. and Bowdrey, J. (2008) Motivational Orientation, Expectancies, and Vulnerability for Depression in Women. Journal of Prevention \& Intervention in the Community, 2, 19-32. http://dx.doi.org/10.1300/J005v35n02_03

[32] Holm, A.L., Lyberg, A., Lassenius, E., Berggren, I. and Severinsson, E. (2013) Older Persons’ Lived Experiences of Depression and Self-Management. Issues in Mental Health Nursing, 10, 757-764. http://dx.doi.org/10.3109/01612840.2013.809829

[33] Holm, A.L., Lyberg, A., Berggren, I., Cutcliffe, J and Severinsson, E. (2014) Shadows from the Past-The Situated Meaning of Being Suicidal among Depressed Older People Living in the Community. Crisis: The Journal of Crisis Intervention and Suicide Prevention, 35, 253-260. http://dx.doi.org/10.1027/0227-5910/a000259

[34] Holm, A.L., Lyberg, A. and Severinsson, E. (2014) Living with Stigma: Depressed Elderly Persons’ Experiences of Physical Health Problems. Nursing Research and Practice, 2014, Article ID: 527920.

http://dx.doi.org/10.1155/2014/527920 
[35] Wade, T.J. and Cairney, J. (1997) Age and Depression in a Nationally Representative Sample of Canadians: A Preliminary Look at the National Population Health Survey. Canadian Journal of Public Health, 88, 297-302.

[36] Fässberg, M.M., Östling, S., Braam, A.W., Bäckman, K., Copeland, J., Fichter, M., Kivelä, S.L., Lawlor, B., Lobo, A., Magnusson, H., Prince, M., Reischies, M., Turrina, C., Wilson, K., Skoog, I. and Waern, M. (2014) Functional Disability and Death Wishes in Older Europeans: Results from the EURODEP Concerted Action. Social Psychiatry and Psychiatric Epidemiology, 49, 1475-1482. http://dx.doi.org/10.1007/s00127-014-0840-1

[37] Hepple, J. and Quinton, C. (1997) One Hundred Cases of Attempted Suicide in the Elderly. British Journal of Psychiatry, 171, 42-46. http://dx.doi.org/10.1192/bjp.171.1.42

[38] Lebret, S., Perret-Vaille, E., Mulliez, A., Gerbaud, L. and Jalenzues, I. (2006) Elderly Suicide Attempters: Characteristics and Outcome. International Journal of Geriatric Psychiatry, 21, 1052-1059. http://dx.doi.org/10.1002/gps.1605

[39] Stroebe, M., Stroebe, W. and Abakoumkin, G. (2005) The Broken Heart: Suicidal Ideation in Bereavement. American Journal of Psychiatry, 162, 2178-2180. http://dx.doi.org/10.1176/appi.ajp.162.11.2178

[40] Kjöseth, I., Ekeberg, O. and Steihaug, S. (2010) Why Suicide? Elderly People Who Committed Suicide and Their Experience of Life in the Period before Their Death. International Psychogeriatrics, 22, 209-218. http://dx.doi.org/10.1017/S1041610209990949

[41] Severinsson, E. and Holm, A.L. (2014) Chronic Disease Management-Implementation and Coordination of Healthcare Systems for Depressed Elderly Persons. Issues in Mental Health Nursing. (Pub Ahead of Print) http://dx.doi.org/10.3109/016/2840.2014.930215

[42] Holm, A.L. and Severinsson, E. (2013) Reflection on the Ethical Dilemmas Involved in Promoting Self-Management. Nursing Ethics, 21, 402-413. http://dx.doi.org/10.1177/0969733013500806 
Scientific Research Publishing (SCIRP) is one of the largest Open Access journal publishers. It is currently publishing more than 200 open access, online, peer-reviewed journals covering a wide range of academic disciplines. SCIRP serves the worldwide academic communities and contributes to the progress and application of science with its publication.

Other selected journals from SCIRP are listed as below. Submit your manuscript to us via either submit@scirp.org or Online Submission Portal.
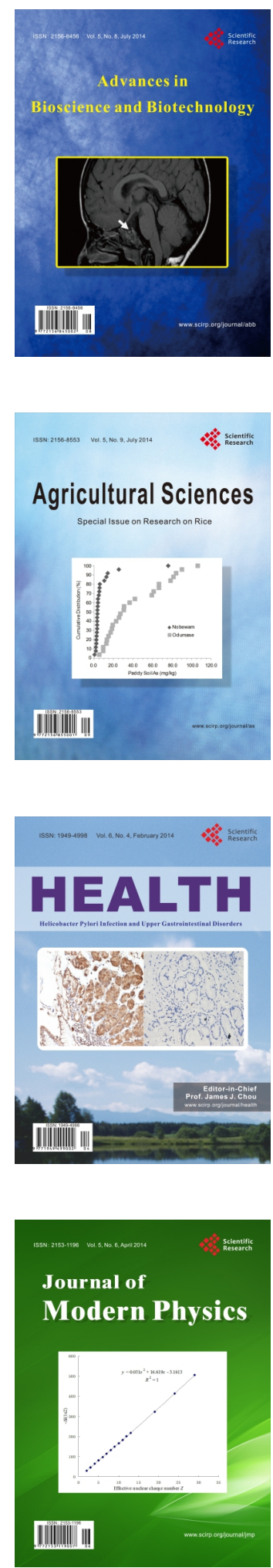
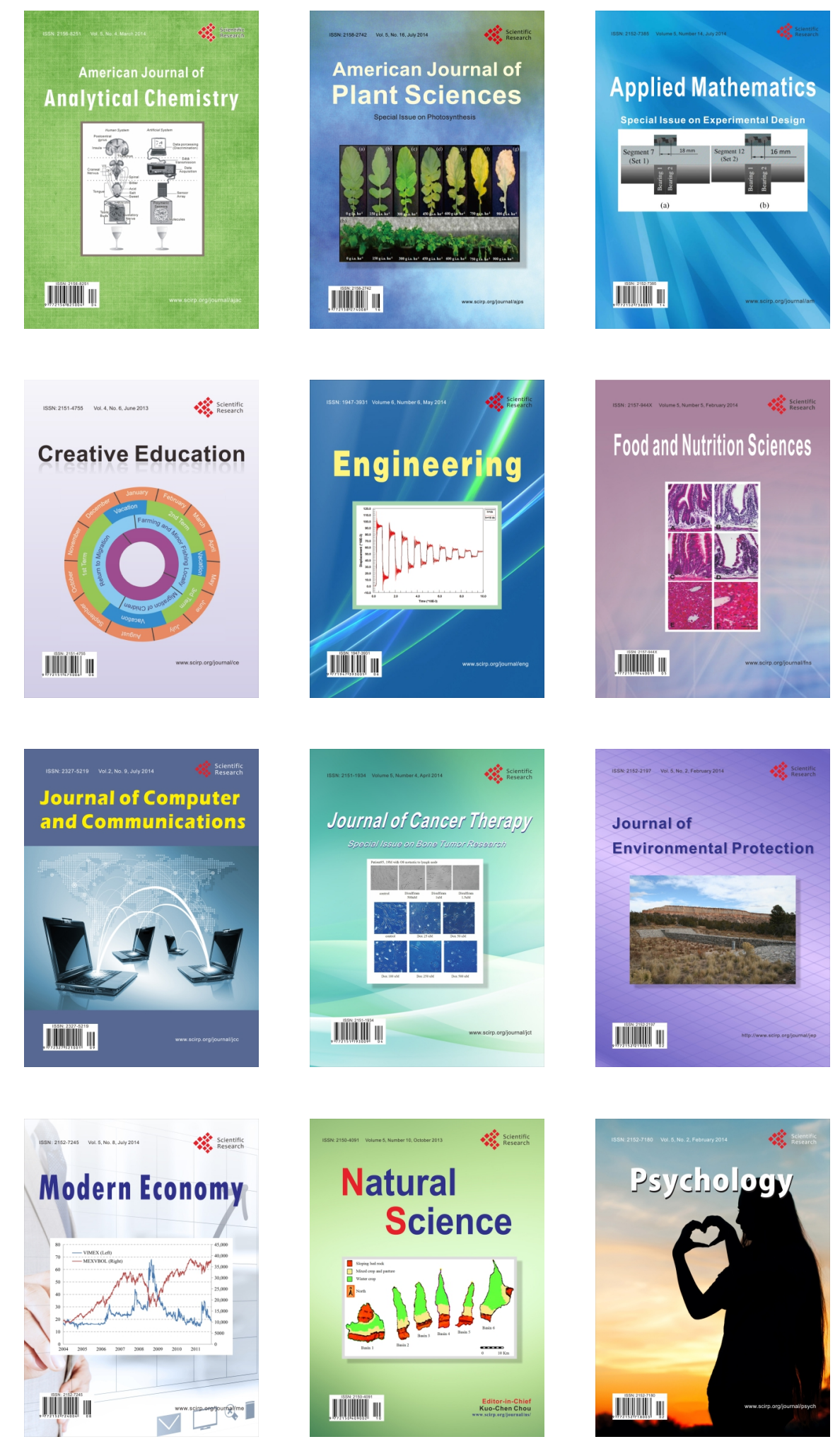